\title{
CORRESPONDENCE
}

\section{MENTAL HANDICAP-THE NATIONAL DEVELOPMENT GROUP REPORT}

\section{DeAr SiR}

The National Development Group for the Mentally Handicapped have been delighted by the generally warm and positive response to our report 'Helping Mentally Handicapped People in Hospital', published in November 1978. Organizations and individuals working full time in the hospital service have seen it as a constructive document, written very much with the needs of residents in mind and containing recommendations which were in line with the thinking of staff about the needs of the service. Many staff and hospital management teams are using the report to secure better resources from Health Authorities.

Dr Shapiro's review (Bulletin, Sept 1979) criticizes what he regards as our neglect of the contribution of medicine in general and psychiatry in particular. This is simply incorrect; we have endorsed the recommendations of the Royal College of Psychiatrists for an increase in consultants to a ratio of 1 per 200,000 population and urge that a consultant should always be a member of the appropriate Joint Care Planning Team. We also suggest a programme of priorities for the recruitment of psychiatrists. Chapter 9 makes it clear that we see the psychiatrist as an indispensable member of Divisional Teams.

However, we make no apologies for accepting a multi-disciplinary model of management. Although this is not without its problems, it has been our impression that most consultants now accept that their colleagues in nursing, psychology, social work and other professions do have a contribution to make in developing a team approach on the basis of partnership and equality, and that the prerogative in making suggestions for better services no longer rests with the consultant alone. This does not, of course, mean that 'clinicians are not to show any initiative but are to sit and wait for administrative pronouncements'. On the contrary, we would hope that consultants, as key members of hospital teams, would do just the opposite.

Dr Shapiro's view that the NDG 'have ignored any positive argument in favour of hospital care' is not borne out by a reading of the report. Chapter 1 contains what we hoped would be a clear position statement; the rest of the report contains many detailed recommendations on how conditions in hospital can be improved for both residents and staff. Of these, Dr Shapiro can only bring himself to remind us that the way to Hell is paved with good intentions. We did hope to have the support of consultants in translating good intentions into better practice.

Dr Shapiro's use of selective quotation cannot be allowed to pass without comment. Since we are alleged to view the hospital as 'a prison without walls', we can only ask readers to look again at the first six paragraphs of Chapter 1 to compare what we did say with Dr Shapiro's caricature of our position. Amongst the other astonishing statements made by Dr Shapiro is that we devote "half a page to behaviour modification', when more than a quarter of the whole report is taken up with guidelines on the training of residents along behavioural lines. These two chapters have been reprinted in large quantities under the title 'Creating a Learning Environment' (free of charge from DHSS Store, Brunswick Street, Nelson, Lancs.) so that copies can be made available to all wards in hospitals and units for the mentally handicapped. It is true that our discussion on residents with behaviour disorders could have been more detailed and that more should have been said about psychiatric disorders, but we did not say that all disturbed behaviour was due to lack of stimulation and boredom'. We did ask for additional resources to provide an active programme of treatment for people with disturbed behaviour, citing the joint report of the Royal College of Psychiatrists and the Royal College of Nursing, as well as the later COHSE report. We also reference a major psychiatric text (Kirman and Bicknell) and two relevant books by paediatricians and refer frequently to published research. But this seems somehow to have escaped Dr Shapiro's attention.

Dr Shapiro's review of our report seems to us to be at best less than fair and at worst a direct misrepresentation of its contents. And how valid is it nowadays to dismiss a report written by a committee with many years' experience of hospital work because it is 'largely composed of laymen'? The use of language of this kind seems to me to be somewhat anachronistic, if not unprofessional.

Dr Shapiro's views on services and on the role of hospitals are well known and extensively

but how far are they shared by the psychiatrists? We do fully agree with

Health Authorities should devote a

scarce resources to the hospital

with this aim in mind that we

Chairman, 